\title{
IDENTIFYING GENDER DIFFERENCES AMONG ROMANIAN NON-SMOKING JUNIOR HIGH SCHOOL STUDENTS
}

\author{
Lucia M. Lotrean ${ }^{1}$, Hein De Vries² \\ 'Department of Hygiene, University of Medicine and Pharmacy, Cluj-Napoca, Romania \\ ${ }^{2}$ Department of Health Education and Promotion, University of Maastricht, The Netherlands
}

\begin{abstract}
SUMMARY
Objectives: The purpose of this study was to assess gender differences regarding perceptions of smoking between Romanian non-smoking boys and girls, to facilitate the development of effective smoking prevention programmes.

Methods: Cross-sectional data were obtained in 2006 by means of written questionnaires among 981 non-smoking school students aged 13-14 years from Cluj-Napoca, Romania.

Results: The results reveal that girls were more convinced than boys that smoking would result in several positive outcomes such as helping them getting more attention and becoming easier part of the crowd. Moreover, girls declared lower self-efficacy in refraining from smoking when friends smoke or offer them a cigarette. Parental norms regarding smoking seem to be less restrictive for boys than for girls.

Conclusions: The gender differences found in our study do not warrant specific smoking prevention programmes for boys and girls, but it is advisable to include gender-specific issues in prevention activities targeting Romanian adolescents aged 13-14 years.
\end{abstract}

Key words: smoking related attitudes, gender differences, Romanian non-smoking adolescents

Address for correspondence: Lucia M. Lotrean, Cezar Petrescu 6, Cluj-Napoca, Romania. E-mail: llotrean@umfcluj.ro

\section{INTRODUCTION}

Smoking is a major preventable cause of premature death and disability throughout the world. In Romania, smoking is responsible for more than 32,000 deaths annually (1).

There are two ways how to decrease morbidity and mortality from smoking related diseases. The first method is to help people not to start smoking and the target population is represented by children and young people, because about $80 \%$ of smoking people became smokers before they were 18 years old; the second method refers to decrease of the number of smokers by using several smoking cessation methods $(1,2,3)$.

Several Eastern European countries including Romania are now at the stage three of the tobacco epidemic, with smoking prevalence among men peaking or just beginning to decline, and smoking prevalence among women still increasing (1).

The European School Project on alcohol, tobacco, and drug use (ESPAD) carried out in 30 European countries showed that in $200364 \%$ of the 16 years old Romanian school students reported smoking at least once during their lifetime, while the prevalence of smoking in the last month was $29 \%$. Both lifetime smoking and smoking in the last month were more frequent among boys $(70 \%$, respectively $32 \%)$ than girls $(59 \%$, respectively $26 \%$ ) (2).

Understanding the psychosocial determinants of smoking is one of the first crucial analyses that should be undertaken in order to understand which specific beliefs should be addressed within intervention programmes in Romania. Moreover, knowledge of potential differences between boys and girls with respect to smok- ing related attitudes and behaviour is also important if we wish to develop smoking prevention programmes that are effectively tailored to the two gender groups (3-5).

In Romania, a recent study focused on gender differences regarding smoking related beliefs of adolescents aged $15-17$ years (6), but no information is known with respect to this issue among younger Romanian adolescents. Hence, the goal of this study is to assess the differences in perceptions about smoking among the Romanian non-smoking boys and girls 13-14 years old.

\section{MATERIALS AND METHODS}

\section{Design and Sample}

The study involved 20 schools from Cluj-Napoca, a city with approximately 330,000 inhabitants situated in the North West part of Romania. The consent for participation was obtained from the school principals, who also offered the number of the 7th grade classes which could participate. The study included junior high school students from 557 th grade classes.

Cross-sectional data were obtained in January 2006 by means of written questionnaires. No refusals were recorded; nonresponse was exclusively due to absence at the day of assessment.

\section{Procedure}

The research team administered the questionnaires. Classroom completion of the questionnaire took approximately 50 minutes. 
Teachers were present during the data collection, but they stayed in the front of the class and were not involved in the collection of questionnaires in order to assure confidentiality. Consent to participate was obtained from the school administration - the standard procedure in Romania.

Students were asked to participate and read an introductory letter. They were assured that the researchers would treat their questionnaires in confidence and it was explained that they could refuse to participate. Students put their completed questionnaires in an envelope, sealed it and the researchers collected the envelopes.

\section{Questionnaire}

An existing questionnaire based on the The I-Change Model (7) was used, piloted, and adapted where needed. The I-Change questionnaire was translated from the version used for OCTOPUS, a European three countries study (8) and for The European Smoking Prevention Framework Approach (ESFA), a collaboration of six European countries (9).

The questionnaire assessed smoking behaviour, attitudes, social influences, self-efficacy expectations, intention and several socio-demographic items (e.g. age, gender).

Smoking behaviour was assessed by asking students to pick a statement that best described them, out of a set of specific smoking-related questions. Responses were cross-validated using an algorithm consisting of concepts measuring current smoking and life-time smoking. Adolescents were then categorized in two groups: smokers and non-smokers. Smokers were defined as smoking at least one cigarette/week or smoking less than weekly, but having smoked more than 100 cigarettes in their lifetime (10, 11). Remaining respondents were classified as non-smokers.

Attitudes were measured on a seven-point scale using 12 items. Six questions assessed the pros of smoking and six other variables assessed the cons of smoking. The pros of smoking referred to expected positive outcomes of smoking (e.g. 'It helps to calm my nerves'; 'It will make me feel relaxed'). The cons of smoking measured the perceived negative outcomes of smoking (e.g. 'It is bad for my health', 'It tastes horrible'). Answering categories ranged from 'I totally disagree' $(=-3)$ to 'I totally agree' $(=+3)$.

Perceived social influences were the social norms, social modeling, and social pressure of father, mother, brother, sister, best friend, friends, and people in the same school year. Social norms were assessed by means of 7 questions on a seven point scale measuring adolescents' perception of whether their parents, siblings, and friends think that they should smoke or not. For example: 'My best friend thinks I definitely should smoke' $(+3)$ to 'definitely should not smoke' $(-3)$.

Social modeling referred to students' perception regarding the smoking behaviour of the social environment. Perceived behaviour of parents, siblings, and best friend was measured on a two-point scale (0-no, 1-yes), while for friends and people in the same year a five-point scale was used (from nobody $=0$ to everybody $=4$ ).

Social pressure assessed the pressure of smoking that students encountered from different persons: parents, siblings, and friends. It was measured by 7 questions on a five point scale ranging from never to very often. For example: 'Have you ever felt pressure to smoke from your best friend?' Answering options were 'very often' (4), 'often' (3), 'sometimes' (2), 'a few times' (1) and 'never' (0).
Self-efficacy expectations to avoid smoking were measured by 12 items on a 7-point scale. The items measure the adolescents' perception of their ability to refrain from smoking when they were pressured by others (e.g. 'when with friends who smoke, are you able not to smoke'), or when under emotional strains (e.g. 'when you feel upset, are you able not to smoke') or when they were in daily routines (e.g. 'when you are watching TV, are you able not to smoke'). Answering categories ranged from 'I am sure I will smoke' (=-3) to 'I am sure I won't smoke' (=+3).

Intention was measured by one question on a seven-point scale and evaluated adolescents' intention to smoke in the next year (+3 definitely; -3 definitely not).

\section{Analysis}

Chi square tests were used to assess gender differences regarding smoking prevalence.

Further analyses included only non-smoking students. Item means were used in order to be able to obtain information about the items that discriminated boys and girls. Independent sample t-tests were used in order to evaluate the differences between girls and boys regarding their attitudes, social influences, self-efficacy beliefs, and intention to smoke in the future.

Data analysis was performed with the SPSS-12 statistical software. Significant results are reported at $\mathrm{p}<0.05$.

\section{RESULTS}

\section{Characteristics of the Sample}

The questionnaires were filled in by 1,196 students. Out of these, $8 \%$ were already smokers. Smoking prevalence was statistically significant $(\mathrm{p}<0.05)$ higher among boys $(10.1 \%)$ than among girls (5.5\%). The present study included only non-smokers students $(\mathrm{N}=981)$. The mean age of the non-smokers was 13.7 $(\mathrm{SD}=0.3$; range $13-14$ years) at $\mathrm{T} 1 ; 52 \%$ were female.

\section{Attitudes Regarding Smoking}

A comparison between girls and boys regarding their attitudes towards advantages of smoking revealed that girls were significantly more convinced than boys that smoking would result in several positive outcomes such as helping them getting more attention and becoming easier part of the crowd. With regard to attitudes toward disadvantages of smoking, both groups perceived many disadvantages and associated smoking with detrimental effects. No gender differences were found (see Table 1).

\section{Social Influences}

As presented in Table 2, girls perceived significantly stronger pressure against smoking from their mother and father, while boys declared higher pressure to smoke coming from their parents. No differences were found between girls and boys regarding perceived smoking behaviour among their mothers and fathers.

At the same time, no significant differences were identified with regard to social influences coming from their siblings. The perceived social norms, social modeling, and social pressure 
Table 1. Differences between non-smoking girls and non-smoking boys regarding attitudes

\begin{tabular}{|c|c|c|c|}
\hline Item & $\begin{array}{c}\text { Girls } \\
\text { Mean (SD) }\end{array}$ & $\begin{array}{c}\text { Boys } \\
\text { Mean (SD) }\end{array}$ & $\mathrm{p}$-value at t-test \\
\hline Pros: I feel more confident in company $(-3$ to +3$)$ & $-0.11(1.23)$ & $-0.20(1.22)$ & Non-significant \\
\hline Pros: It helps to calm my nerves $(-3$ to +3$)$ & $0.29(0.96)$ & $0.31(1.01)$ & Non-significant \\
\hline Pros: It will make me feel relaxed $(-3$ to +3$)$ & $-0.09(1.12)$ & $-0.04(1.32)$ & Non-significant \\
\hline Pros: It helps me to be slim $(-3$ to +3$)$ & $0.30(0.77)$ & $0.26(0.63)$ & Non-significant \\
\hline Pros: It is easier to be part of the crowd $(-3$ to +3$)$ & $0.15(1.32)$ & $-0.10(1.59)$ & $p<0.05$ \\
\hline Pros: My friends will pay me more attention $(-3$ to +3$)$ & $-0.12(1.22)$ & $-0.40(1.62)$ & $p<0.05$ \\
\hline Cons: It is bad for my health $(-3$ to +3$)$ & $2.62(0.62)$ & $2.58(0.77)$ & Non-significant \\
\hline Cons: It is stupid of me $(-3$ to +3$)$ & $2.17(1.27)$ & $2.22(1.48)$ & Non-significant \\
\hline Cons:I consider my behaviour to be wrong $(-3$ to +3$)$ & $2.42(1.01)$ & $2.45(0.99)$ & Non-significant \\
\hline Cons: If I will get sick, I will be sorry that I ever started $(-3$ to +3$)$ & $2.59(0.83)$ & $2.56(0.96)$ & Non-significant \\
\hline Cons: It tastes horrible $(-3$ to +3$)$ & $1.80(1.48)$ & $1.76(1.48)$ & Non-significant \\
\hline Cons: I believe it to be unfriendly $(-3$ to +3$)$ & $0.83(1.36)$ & $0.84(1.33)$ & Non-significant \\
\hline
\end{tabular}

Table 2. Differences between non-smoking girls and non-smoking boys regarding social influences

\begin{tabular}{|c|c|c|c|}
\hline Item & $\begin{array}{c}\text { Girls } \\
\text { Mean (SD) }\end{array}$ & $\begin{array}{c}\text { Boys } \\
\text { Mean (SD) }\end{array}$ & $\mathrm{p}$-value at t-test \\
\hline \multicolumn{4}{|l|}{ Social norms } \\
\hline Mother $(-3$ to +3$)$ & $-2.66(0.75)$ & $-2.44(0.60)$ & $p<0.05$ \\
\hline Father $(-3$ to +3$)$ & $-2.55(0.98)$ & $-2.40(0.84)$ & $p<0.05$ \\
\hline Brother(s) $(-3$ to +3$)$ & $-1.22(1.33)$ & $-1.20(1.26)$ & Non-significant \\
\hline Sister(s) $(-3$ to +3$)$ & $-1.21(1.36)$ & $-1.16(1.29)$ & Non-significant \\
\hline Friends $(-3$ to +3$)$ & $-1.52(1.43)$ & $-1.37(1.43)$ & Non-significant \\
\hline Best friend $(-3$ to +3$)$ & $-2.01(1.16)$ & $-1.99(1.26)$ & Non-significant \\
\hline People in the same school year $(-3$ to +3$)$ & $-0.93(1.37)$ & $-1.12(1.40)$ & Non-significant \\
\hline \multicolumn{4}{|l|}{ Perceived behaviour } \\
\hline Mother ( 0 to 1$)$ & $0.34(0.48)$ & $0.33(0.48)$ & Non-significant \\
\hline Father (0 to 1) & $0.43(0.49)$ & $0.42(0.48)$ & Non-significant \\
\hline Brother(s) (0 to 1) & $0.06(0.36)$ & $0.05(0.32)$ & Non-significant \\
\hline Sister(s) (0 to 1) & $0.04(0.26)$ & $0.03(0.29)$ & Non-significant \\
\hline Friends (0 to 4$)$ & $0.74(1.42)$ & $0.71(1.17)$ & Non-significant \\
\hline Best friend ( 0 to 1 ) & $0.10(0.37)$ & $0.09(0.41)$ & Non-significant \\
\hline People in the same school year (0 to 4 ) & $0.53(1.25)$ & $0.43(1.14)$ & $p<0.05$ \\
\hline \multicolumn{4}{|l|}{ Social pressure } \\
\hline Mother (0 to 4) & $0.03(0.29)$ & $0.09(0.21)$ & $p<0.05$ \\
\hline Father (0 to 4) & $0.01(0.33)$ & $0.14(0.09)$ & $p<0.05$ \\
\hline Brother(s) (0 to 4) & $0.04(0.39)$ & $0.08(0.53)$ & Non-significant \\
\hline Sister(s) (0 to 4) & $0.08(0.43)$ & $0.04(0.09)$ & Non-significant \\
\hline Friends (0 to 4) & $0.46(0.97)$ & $0.48(0.88)$ & Non-significant \\
\hline Best friend ( 0 to 4$)$ & $0.20(0.59)$ & $0.17(0.71)$ & Non-significant \\
\hline People in the same school year (0 to 4 ) & $0.28(0.85)$ & $0.31(0.86)$ & Non-significant \\
\hline
\end{tabular}

coming from students' colleagues, friends, and best friend was similar for boys and girls, with the exception that girls perceived more smoking behaviour among their colleagues.

\section{Self-efficacy Expectations and Intention}

Table 3 shows that non-smoking students had great confidence in their ability to refuse smoking in several situations. 
Table 3. Differences between non-smoking girls and non-smoking boys regarding self-efficacy and intention

\begin{tabular}{|l|c|c|c|}
\hline Item & $\begin{array}{c}\text { Girls } \\
\text { Mean (SD) }\end{array}$ & $\begin{array}{c}\text { Boys } \\
\text { Mean (SD) }\end{array}$ & p-value at t-test \\
\hline When with people who smoke $(-3$ to +3$)$ & $2.35(1.01)$ & $2.44(1.05)$ & Non-significant \\
\hline When with friends who smoke $(-3$ to +3) & $2.20(1.11)$ & $2.32(0.97)$ & p<0.05 \\
\hline When you are offered a cigarette $(-3$ to +3) & $2.33(0.93)$ & $2.38(0.83)$ & Non-significant \\
\hline When friends offer you a cigarette $(-3$ to +3) & $2.24(1.10)$ & $2.40(0.83)$ & p<0.05 \\
\hline When you are shopping $(-3$ to +3$)$ & $2.62(0.49)$ & $2.55(0.53)$ & Non-significant \\
\hline When you are watching TV $(-3$ to +3$)$ & $2.69(0.49)$ & $2.65(0.50)$ & Non-significant \\
\hline When you are doing homework $(-3$ to +3$)$ & $2.66(0.48)$ & $2.63(0.45)$ & Non-significant \\
\hline When you are on your way from school $(-3$ to +3$)$ & $2.60(0.53)$ & $2.59(0.49)$ & Non-significant \\
\hline When you feel upset $(-3$ to +3$)$ & $2.31(1.21)$ & $2.36(0.96)$ & Non-significant \\
\hline When you feel depressed $(-3$ to +3$)$ & $2.39(1.25)$ & $2.43(0.91)$ & Non-significant \\
\hline When you feel nervous $(-3$ to +3$)$ & $2.33(1.26)$ & $2.41(1.05)$ & Non-significant \\
\hline When you are worried $(-3$ to +3$)$ & $2.41(1.03)$ & $2.48(0.80)$ & Non-significant \\
\hline Intention(-3 to +3) & $-2.25(1.31)$ & $-2.42(0.97)$ & p<0.05 \\
\hline
\end{tabular}

Nevertheless, statistically significant more girls reported lower self-efficacy expectations about non-smoking in social situations, especially when they are together with smoking friends and are offered a cigarette.

Although both groups had negative intention to start smoking in the next year, girls were, however, less confident about it.

\section{DISCUSSIONS}

The purpose of this study was to assess gender differences regarding perceptions of smoking between Romanian non-smoking boys and girls, in order to facilitate the development of effective smoking prevention programmes.

As reported by other researchers, the process of becoming a smoker and the different stages one goes through from starting to smoke to becoming a regular smoker is fairly similar for both boys and girls, but the motives why adolescents start and maintain smoking habit may differ between boys and girls $(3,4,6,12)$. Nevertheless, data on gender differences from other countries suggest that our understanding of the effect of gender on smoking initiation is limited (12-16).

The results of our study reveal several differences between Romanian male and female non-smokers aged 13-14 years regarding their attitudes, social influences, and self-efficacy with respect to smoking behaviour. Smoking is believed to help girls get more attention and become part of the crowd. Studies from other countries also found that smoking was considered by the girls as a way to reinforce friendship and to increase the feeling of belonging to a group $(12,17)$.

Moreover, girls declared lower self-efficacy in refraining from smoking when friends smoke or offer them a cigarette. Studies from other countries also underline that girls are more sensitive to peer influences (3) and have more doubts than boys about their capacity to refuse cigarettes when these are offered them (12).
On the other hand, parental norms regarding smoking seem to be less restrictive for Romanian boys than for Romanian girls.

A very interesting finding of the study is that smoking prevalence was higher among boys, but more non-smoking girls than non-smoking boys declared higher intention to start smoking in the next year. It is conceivable that more boys experiment with smoking at earlier ages and are already smokers when they arrived in the last years of junior high school. On the other hand, the last years of junior school could make some of the girls to think about starting smoking, possibly as a way of socializing and comparing positively with other girls.

Our study is subject to limitations. First, the study sample consisted of junior high school students from Cluj-Napoca. This is one of the main cities of Romania, but it is inevitably a limit to generalization of the study findings beyond this sample. Second, the self-reported smoking behaviour was not validated by biochemical measures. However, self-reports have been shown to be reliable and in good agreement with biological indicators when anonymity is assured (18). We optimized measurement conditions by assuring respondents that their responses would be treated as strictly confidential. Third, the reports on parents, siblings, and friends smoking were based on the adolescents' own perception.

The gender differences found in our study do not warrant specific smoking prevention programmes for boys and girls, but it is advisable to include gender-specific issues in prevention programmes targeting Romanian adolescents aged 13-14 years. Girls may benefit more from a programme which focus on changing the positive image of smoking as well as on teaching specific skills to resist pressures from friends which might also influence self-efficacy expectations. Moreover, the smoking prevention programmes might have stronger effects by exposing entire peer groups to the intervention. At the same time, parents should be informed and motivated to have stricter rules against smoking also for their male children.

Hence, the information offered by this study will help the development of appropriate school-based policies and educa- 
tional programmes for smoking prevention among Romanian adolescents as an important part of comprehensive tobacco control measures in this country.

\section{Acknowledgement:}

This study was funded by grant PN-II-RU-TE-2011-3-0192.

Conflict of interest: None declared.

\section{REFERENCES}

1. Shafey O, Dolwick S, Guindon GE, editors. Tobacco control country profiles 2003. Atlanta, GA: American Cancer Society; 2003.

2. Romanian Ministry of Health. The European school survey project on alcohol and other drugs. Bucharest: The Ministry; 2004.

3. Hoving C, Reubsaet A, de Vries H. Predictors of smoking stage transitions for adolescent boys and girls. Prev Med. 2007 Jun;44(6):485-9.

4. Amos A, Bostock Y. Young people, smoking and gender - a qualitative exploration. Health Educ Res. 2007 Dec;22(6):770-81.

5. Markham WA, Aveyard P, Thomas H, Charlton A, Lopez ML, De Vries $\mathrm{H}$. What determines future smoking intentions of 12- to 13-year-old UK African-Caribbean, Indian, Pakistani and white young people? Health Educ Res. 2004 Feb;19(1):15-28.

6. Lotrean LM, Mesters I, Ionut C, de Vries H. Smoking among Romanian adolescents: do the gender differences exist? Pneumologia. 2009 OctDec;58(4):240-6.

7. Ausems M, Mesters I, van Breukelen G, De Vries H. Short-term effects of a randomized computer-based out-of-school smoking prevention trial aimed at elementary schoolchildren. Prev Med. 2002 Jun;34(6):581-9.

8. de Vries H, Mudde A, Leijs I, Charlton A, Vartiainen E, Buijs G, et al. The European Smoking Prevention Framework Approach (EFSA): an example of integral prevention. Health Educ Res. 2003 Oct;18(5):611-26.
9. de Vries H, Dijk F, Wetzels J, Mudde A, Kremers S, Ariza C, et al. The European Smoking prevention Framework Approach (ESFA): effects after 24 and 30 months. Health Educ Res. 2006 Feb;21(1):116-32.

10. de Vries H, Mudde A, Kremers S, Wetzels J, Uiters E, Ariza C, et al. The European Smoking Prevention Framework Approach (ESFA): short-term effects. Health Educ Res. 2003 Dec;18(6):649-63; discussion 664-77.

11. Centers for Disease Control and Prevention. Behavioral Risk Facto Surveillance System; 2002 [Internet]. 2001 [cited 2006 Jan 1]. Available from: http://www.cdc.gov/brfss/questionnaires/pdf-ques/2002brfss.pdf.

12. Lambert $M$, editor. Report on gender differences in smoking in young people. Brussels: Flemish Institute for Health Promotion; 2002.

13. US Department of Health and Human Services. Preventing tobacco use among young people: a report of the Surgeon General. Atlanta, GA: US Department of Health and Human Services; 1994.

14. Piko BF, Wills TA, Walker C. Motives for smoking and drinking: country and gender differences in samples of Hungarian and US high school students. Addict Behav. 2007 Oct;32(10):2087-98.

15. Kim H, Kim EK, Choi ES, Kim YJ, Lee HJ, Kim JJ, et al. The determinants of adolescent smoking by gender and type of school in Korea. J Prev Med Public Health. 2006 Sep;39(5):379-88. (In Korean.)

16. Kaleta D, Usidame B, Polańska K. Tobacco advertisements targeted on women: creating an awareness among women. Cent Eur J Public Health. 2011 Jun;19(2):73-8.

17. Babar AA, Stigler MH, Perry CL, Arora M, Shrivastav R, Reddy KS. Tobacco-use psychosocial risk profiles of girls and boys in urban India: implications for gender-specific tobacco intervention development. Nicotine Tob Res. 2010 Jan;12(1):29-36.

18. Dolcini MM, Adler NE, Ginsberg D. Factors influencing agreement between self-reports and biological measures of smoking among adolescents. J Res Adolesc. 1996;6(5):515-42.

Received October 14, 2011 Accepted in revised form January 27, 2012 